\title{
An Overview of the Evidence for Psychological Interventions for Psychosis: Results From Meta-Analyses
}

\author{
Tania M. Lincoln ${ }^{\mathrm{a}}$, Anya Pedersen ${ }^{\mathrm{b}}$ \\ [a] Institute of Psychology, Universität Hamburg, Hamburg, Germany. [b] Institute of Psychology, Christian-Albrechts- \\ Universität, Kiel, Germany.
}

Clinical Psychology in Europe, 2019, Vol. 1(1), Article e31407, https://doi.org/10.32872/cpe.v1i1.31407

Received: 2018-11-06 • Accepted: 2019-02-13 • Published (VoR): 2019-03-29

Handling Editor: Winfried Rief, Division of Clinical Psychology and Psychotherapy, Department of Psychology, Philipps-University of Marburg, Marburg, Germany

Corresponding Author: Tania M. Lincoln, Universität Hamburg, Institut für Psychologie, Klinische Psychologie und Psychotherapie, Von-Melle-Park 5, 20146 Hamburg, Germany. E-mail: tania.lincoln@uni-hamburg.de

\section{Abstract}

Background: There are numerous psychological approaches to psychosis that differ in focus, specificity and formats. These include psychodynamic, humanistic, cognitive-behavioural and third-wave-approaches, psychoeducation, various types of training-based approaches and family interventions.

Method: We briefly describe the main aims and focus of each of these approaches, followed by a review of their evidence-base in regard to improvement in symptoms, relapse and functioning. We conducted a systematic search for meta-analyses dating to 2017 for each of the approaches reviewed. Where numerous meta-analyses for an approach were available, we selected the most recent, comprehensive and methodologically sound ones.

Results: We found convincing short- and long-term evidence for cognitive behavioural approaches if the main aim is to reduce symptom distress. Evidence is also strong for psychoeducative family interventions that include skills training if the main aim is to reduce relapse and rehospitalisation. Acceptance and commitment therapy, mindfulness-based approaches, meta-cognitive and social skills training, as well as systemic family interventions, were also found to be efficacious, depending on the outcome of interest, but meta-analyses for these approaches were based on a comparatively lower number of outcome studies and a narrower selection of outcome measures. We found no convincing evidence for psychodynamic approaches, humanistic approaches or patient-directed psychoeducation (without including the family).

Conclusions: An array of evidence-based psychological therapies is available for psychotic disorders from which clinicians and patients can choose, guided by the strength of the evidence and depending on the outcome area focused on. Increased effort is needed in terms of dissemination and implementation of these therapies into clinical practice. 


\section{Keywords}

psychosis, schizophrenia, psychological therapy, intervention, evidence

\section{Highlights}

- Meta-analyses show convincing evidence for CBT if the main target is psychotic symptoms.

- Meta-analyses show convincing evidence for family interventions if the main target is relapse.

- Effects are promising for ACT, mindfulness-based and systemic approaches, but more research is needed.

- The array of effective approaches allows clinicians and patients to select the most appropriate one.

Patients with psychotic disorders often face a diverse and complex set of problems. One part of these problems are the symptoms as such. These include persecutory delusions, hearing voices and feeling driven, or negative symptoms, such as the loss of drive. Not only do these symptoms tend to cause severe distress (Lincoln, 2007; Woodward et al., 2014), they can also be accompanied by an array of interpersonal problems or social withdrawal (Depp et al., 2016; Mondrup \& Rosenbaum, 2009). Accordingly, relatives and other people involved also often report difficulties in communication or feeling helpless (Treanor, Lobban, \& Barrowclough, 2013). Moreover, an acute episode that might have involved voluntary or involuntary hospitalisation can be traumatizing (Paksarian et al., 2014) and many patients and relatives report continuous worry about possible relapse (Gumley et al., 2015; Lal et al., 2019). Unsurprisingly, therefore, many patients and their relatives seek professional help.

Since the discovery of antipsychotic drugs in the early 1950s, this help has been primarily pharmacological in nature. Although medication is valuable in the acute phase, the effect sizes in randomised trials for medication alone are only small to moderate (Leucht et al., 2012) and may come at the cost of disadvantageous long-term side effects (Murray et al., 2016). Also, medication is not well accepted by many patients (Wade, Tai, Awenat, \& Haddock, 2017). Based on the requirement to inform evidence-based additions and alternatives to antipsychotic medication (Morrison, Hutton, Shiers, \& Turkington, 2012), and an increasingly better understanding of the psychological mechanisms that cause and maintain psychotic symptoms (for a comprehensive and service-user oriented overview of this research see Cooke, 2014) different psychological approaches have been developed over the past decades. These differ in their focus and formats, but ultimately all aim to help patients to either overcome or to cope better with symptoms and to improve functioning and well-being. 


\section{Methods of the Review}

The scope of the present review covers the efficacy of different psychological approaches for psychosis offered in combination with pharmacotherapy as reflected in meta-analyses.

A systematic search for methodologically sound meta-analyses via Web of Science, PsycINFO, PSYNDEX, and Medline was conducted to establish a German guideline for the psychological treatment of schizophrenia and psychotic disorders (Lincoln, Pedersen, Hahlweg, Wiedl, \& Frantz, 2019). This guideline was initiated by the German Society for Clinical Psychology and Psychotherapy as an adjunct to the S-3 German guideline, which has a broader focus. Considering recommendations by the Association of the Scientific Medical Societies in Germany (AWMF), evidence derived for the different psychological approaches is based on recent meta-analyses including well-conducted randomised controlled trials (RCTs). Starting out from the comprehensive meta-analysis on the treatment and management of psychosis and schizophrenia in adults (National Collaborating Centre for Mental Health [NCCMH], 2014 [Update]) conducted for the NICE-guidelines (National Institute for Health and Care Excellence) in 2009 we searched the literature from 2010 to 2017 for additional meta-analyses (Note. The guideline covered research until 2016. For the present overview we updated this search to cover meta-analyses published up to the end of 2017). When a psychological approach was not covered in the NICEguidelines (NCCMH, 2014), we additionally searched for meta-analyses published before 2010. The identified meta-analyses were critically appraised for methodological quality as well as overlap and we selected the most recent, comprehensive and methodologically sound analyses (e.g. conducted by the Cochrane Collaboration or other independent researchers). A complete list of the reviewed and selected meta-analyses is added in the Appendix. Meta-analyses were included if they focused on schizophrenia, delusional disorders, schizoaffective disorders and acute and transient psychotic disorders following DSM-III-R, DSM-IV or DSM-5 criteria.

The outcome measures covered include improvement in symptoms (overall symptoms, positive symptoms and negative symptoms), relapse rates and rehospitalisations as well as psychosocial functioning.

Psychological approaches reviewed covered individual and group interventions conducted within in- and out-patient settings. We report the effectiveness of each approach on the basis of randomised-controlled trials that compared the approach either to the usual treatment (TAU; e.g. pharmacotherapy and consultation) condition alone or to a TAU plus an active control condition (e.g. supportive therapy or psychoeducation) at post-treatment and/or at follow-up (ranging from weeks to years). In order to be able to compare the effectiveness of these approaches we focus on comparisons to "any control", because meta-analyses on approaches which have not been comprehensively investigated often do not differentiate between comparisons to TAU versus active controls. Only effect sizes based on at least two independent original studies were considered. 


\section{Description of the Reviewed Approaches and Their Respective Evidence Basis}

\section{Cognitive Behavioural Therapy for Psychosis}

\section{Description}

Cognitive behavioural interventions for psychosis (CBTp) build on the assumption that psychotic symptoms lie on a continuum with normal experiences. They are also informed by research suggesting that psychotic experiences result from normal, though exaggerated, mechanisms of perception and reasoning. This understanding has formed the basis for cognitive models of psychosis. As one of the most influential of these models, Garety, Kuipers, Fowler, Freeman, \& Bebbington (2001) postulate that psychotic symptoms develop when stressors overload a person, causing them to have unusual experiences. According to this model, not the unusual experience itself is crucial but its appraisal. A variety of approaches within the CBTp-framework have been described (Fowler, Garety, \& Kuipers, 1995; Morrison, Renton, Dunn, Williams, \& Bentall, 2004). Most descriptions converge in stressing the importance of building a stable therapeutic relationship through the process of listening and validating, of taking a collaborative approach and of working with an individual case formulation. The use of cognitive and behavioural interventions for working with psychotic symptoms as well as for changing dysfunctional beliefs and interventions to prevent relapse are also essential elements.

\section{Evidence Base}

Beyond the NICE-Meta-Analysis conducted in 2009 our review is based on seven further meta-analyses (Burns, Erickson, \& Brenner, 2014; Jauhar et al., 2014; Jones, Hacker, Cormac, Meaden, \& Irving, 2012; Lutgens, Gariepy, \& Malla, 2017; Turner, van der Gaag, Karyotaki, \& Cuijpers, 2014; van der Gaag, Valmaggia, \& Smit, 2014; Velthorst et al., 2015) selected from a larger pool of 13 meta-analyses.

As can be seen in Table 1, with the exception of the Cochrane-analysis by Jones et al., (2012), the meta-analyses consistently detected small effects on overall symptoms at posttreatment and at various follow-up periods favouring CBTp over TAU. The findings were less consistent, however, when CBTp was compared to active control. The picture is similar for positive symptoms, with Jones et al. (2012) reporting mixed findings, while the other meta-analyses consistently revealed effects in favour of CBTp compared to TAU, both at post-treatment and at follow-ups. Again, the comparisons to active control groups were less consistent. For negative symptoms there were small post-therapy effects (Jauhar et al., 2014; Lutgens et al., 2017) and small follow-up effects (NCCMH, 2014), overall, however, the non-significant findings outweighed the significant ones. Relapse rates, rehospitalisations and functioning were only investigated in two meta-analyses (Jones et al., 2012; NCCMH, 2014), and are based on a smaller number of studies. Neither meta-analy- 
sis showed an effect on relapse and the effects for rehospitalisations and functioning were mixed.

\section{Third-Wave-Approaches to Psychosis}

\section{Description}

Third-wave-approaches are new developments in CBT which emphasise the relevance of acceptance, mindfulness and emotions, the relationship, values, goals, and meta-cognition (Hayes \& Hofmann, 2017). In psychosis, adaptations of mindfulness-based therapy, acceptance and commitment therapy (ACT) and compassion focused therapy (CFT) have been studied most. In order to ease distress and achieve acceptance as well as to support the regaining of control, mindfulness-based interventions for psychosis guide patients to notice sensations and their own emotional and cognitive reactions to them with awareness (Chadwick, 2014). In meditation-based practices, patients learn to observe their thoughts, feelings and symptoms in an accepting and non-judgmental way. Mindfulness interventions for psychosis have been implemented as single treatments (e.g. Chadwick, 2014) or combined with CBT (e.g. Wright et al., 2014).

In ACT (Hayes, Strosahl, \& Wilson, 1999) experiential avoidance and cognitive fusion are suggested to be the core processes of suffering. In order to increase psychological flexibility and reduce distress associated with psychotic symptoms, patients are guided to develop a balance between committed value-guided action when solving actual problems and acceptance when control of thoughts and feelings is limited (e.g. in the case of hallucinations). ACT has been adapted for the treatment of psychosis (O’Donoghue, Morris, Oliver, Johns, \& Hayes, 2018; combined with CBT, Wright et al., 2014).

Compassion-focused therapy (CFT, Gilbert \& Procter, 2006) encourages patients to be more compassionate towards themselves and others while reducing shame and self-criticism. Compassionate mind training includes appreciation and imagery exercises as well as aspects of mindfulness and aids the patient to experience different aspects of compassion in order to promote mental wellbeing. CFT has been adapted for the treatment of psychosis (Brähler, Harper, \& Gilbert, 2013).

\section{Evidence Base}

We selected two (Cramer, Lauche, Haller, Langhorst, \& Dobos, 2016; Louise, Fitzpatrick, Strauss, Rossell, \& Thomas, 2018) from an identified pool of four meta-analyses. No metaanalysis reported effects-sizes for CFT based on more than one original study, hence, only mindfulness-based interventions and ACT are reviewed.

Both meta-analyses revealed no significant effect of ACT, but a significant small effect of mindfulness-based interventions on overall symptoms at post-treatment (Cramer et al., 2016; Louise et al., 2018). One meta-analysis analysed the effect at follow-up and reported an even increased effect (Cramer et al., 2016). 
ACT showed a significant moderate effect on positive symptoms, but not on negative symptoms at post-treatment (Cramer et al., 2016).

The number of rehospitalisations was only investigated for ACT, revealing a significant small effect (based on two studies; Cramer et al., 2016). Relapse and functioning were not analysed.

\section{Psychodynamic Therapy for Psychosis}

\section{Description}

Early psychoanalytic conceptions of psychosis understand psychotic symptoms as a manifestation of the mind being invaded by the unconscious and by dreams (Federn, 1928/1952). More contemporary approaches underline the importance of early relationship patterns (e.g. Bion, 1962; Winnicott, 1991). Internal representations of experiences with significant others and current relationships are assumed to result in tension and psychotic symptoms are considered as a "constructive" way of dealing with this tension (von Haebler \& Freyberger, 2013). Psychodynamic therapy focuses on these processes and helps the patient to gain self-awareness and understanding of the influence of the past on present behaviour and it fosters new positive relationship experiences. An empathic, respectful and supportive attitude allows re-enactment of internalised relational patterns in the therapist-patient interaction (Lempa, Montag, \& von Haebler, 2013).

\section{Evidence Base}

We identified two meta-analyses. However, both the meta-analysis conducted for the NICE-guidelines (NCCMH, 2014) and the one of the Cochrane Collaboration (Malmberg, Fenton, \& Rathbone, 2001) were based on four original studies only. The aggregated data of the two analyses did not indicate significant improvement in overall symptoms, functioning (NCCMH, 2014) or rehospitalisations (Malmberg et al., 2001) in patients treated with psychodynamic therapy compared to any control. The inclusion criteria for the present review were not fulfilled as none of the relevant outcome measures were covered by more than one original study; hence, psychodynamic therapies are not included in Table 1.

\section{Humanistic or Client-Centred Approaches}

\section{Description}

In client-centred or humanistic therapy, unconditional positive regard, accurate empathy and genuineness are assumed to help a patient to increase the congruence between the real self and the ideal self (Rogers, Gendlin, Kiesler, \& Truax, 1967). Rogers and colleagues' concept of "actualizing tendency" points to an inherent tendency to achieve personal growth and reach one's full potential. In this framework psychotic symptoms are understood as a distortion of this actualising tendency. Client-centred therapy focuses on 
personal experiences, whereas relieving specific symptoms is secondary. Thus, no specific therapeutic strategies have been established for psychosis. However, therapists are recommended to pay particular attention to understanding the client's perspective, ensuring that the patient is being heard and emphasising the personal relationship (Gendlin, 1962).

\section{Evidence Base}

Client-centred or humanistic therapy for psychosis has not been covered in a meta-analysis and the only known RCT dates back to 1967 (Rogers) and did not reveal convincing effects.

\section{Psychoeducation for Patients}

\section{Description}

To enhance knowledge and understanding of psychosis and to improve coping skills psycho-educational interventions are routinely offered in the treatment of psychosis. Mainly in group format, patients receive systematic and structured information on psychosis and its consequences, early warning signs, triggering and maintaining factors, relapse prevention, and modalities of treatment. Psychoeducation aims to help patients to increasingly take personal responsibility and improve coping skills.

\section{Evidence Base}

Two comprehensive meta-analyses (NCCMH, 2014; Turner et al., 2014) that provided sub-analyses on the effect of psychoeducation for patients without involving family members did not show any significant effect of psychoeducation on overall symptoms, positive or negative symptoms (Turner et al., 2014), relapse rates or rehospitalisations (NCCMH, 2014).

\section{Training-Based Approaches}

\section{Description}

From the range of different training-based approaches that cannot be fully covered within the scope of this review, we exemplarily focus on two widely used training-based interventions - one targeting positive symptoms (Metacognitive training) and one primarily addressing negative symptoms (Social skills training).

Metacognitive training (MCT; Moritz \& Woodward, 2007) was designed to address positive symptoms in patients with schizophrenia. As cognitive biases have been related to positive symptoms (e.g. jumping to conclusions or externalizing attributional bias, see Garety \& Freeman, 1999), MCT aims to extent patient's knowledge of cognitive biases and to provide corrective experiences. Implementing a wide range of examples and exercises, patients participating in a MCT group training are encouraged to identify and gain 
insight into these cognitive biases and reduce conviction in delusional ideas. MCT is mainly administered in group format.

Social skills trainings (SST) build on the observation that patients with psychotic disorders tend to show impaired social skills. SST involve therapist modelling and instructing socially confident behaviour in specific situations combined with role-plays. Patients receive supportive feedback from the therapist and video feedback can also be used. During the end of the training that usually takes place in group-format patients are encouraged to practice the newly learnt skills in daily life. A frequently used treatment manual was published by Bellack, Mueser, Gingerich, and Agresta (2013).

\section{Evidence Base for MCT}

A significant small effect on positive symptoms was reported in two of three identified meta-analyses on the effect of MCT in psychosis (Eichner \& Berna, 2016; Jiang, Zhang, Zhu, Li, \& Li, 2015), whereas one did not reveal a significant effect at post-treatment (van Oosterhout et al., 2016). Regarding overall and negative symptoms, relapse / rehospitalisations and functioning no aggregated effect sizes were reported.

\section{Evidence Base for Social Skill Trainings}

We identified and included three meta-analyses: the NICE meta-analysis (NCCMH, 2014), the Cochrane meta-analysis (Almerie et al., 2015) and the meta-analysis by Turner et al. (2014). There was no effect of SST on overall symptoms compared to control conditions at post-therapy in any of the meta-analyses, follow-up effects were not reported. There was also no effect in favour of SST for positive symptoms (Turner et al., 2014). For negative symptoms there were significant post-therapy effects (NCCMH, 2014; Turner et al., 2014). A significant follow-up effect for SST versus TAU was found in one meta-analysis (Almerie et al., 2015). For relapse and rehospitalisation, the findings were mixed. There was no significant effect for functioning, neither at post-assessment nor at follow-up.

\section{Family Interventions}

\section{Description}

Interventions that include the family are subsumed under the term "family intervention". The patient may be included in all, some, or - in some programmes - no sessions. Depending on the approach, a family intervention will involve 12 to 25 treatment sessions during the course of a year or longer and accompany the family through the remission phase. The diverse approaches can be broadly subdivided into psycho-educative family interventions, comprehensive interventions that combine information with problemsolving, social and communication skills, and systemic family interventions.

The psychoeducational approach builds on the observation that patients with psychosis often rely on relatives for support (Dixon, Adams, \& Lucksted, 2000) and the assump- 
tion that involved family members thus require information and assistance to cope with the challenges posed to the family system. It thus conveys basic knowledge about psychosis, building on the vulnerability-stress models. It sees psychosis as mental illness and enlists family members as therapeutic agents, taking care not to make the relatives feel blamed (Lucksted, McFarlane, Downing, \& Dixon, 2012). It aims to convey the relevance of medical and psychosocial treatment, reduce misconceptions and provide a basis on which to promote the self-management skills, improve family coping and reduce relapse.

The skill-training approach builds on findings showing higher rates of relapse if a patient's family displays a communication style characterised by high levels of criticism, hostility, or emotional over-involvement ("high expressed emotion”, Butzlaff \& Hooley, 1998). It builds on the assumption that problems that arise from caring for a mentally ill family member can be solved if the family develops good problem solving strategies and a supportive way of communicating. The therapist models the verbal and non-verbal communication rules and assists the family to use the communication skills in a series of role-plays. The improved skills are then used to solve practical problems within the family context, using a problem solving approach. A well-established program of this type is described by Falloon, Boyd, and McGill, (1984).

Systemic approaches assume that relationships within the family (or other relevant social systems) influence the feelings, beliefs and behaviour of the "index patient" and vice versa and therefore, that psychotic symptoms may have arisen from specific interaction patterns within the family. The therapy aims to identify and change these patterns in order to reduce symptoms. If, for example, family members have stopped communicating about relevant issues with the patient, the therapist would attempt to re-include the patient in the communication processes. Changes in interactions are promoted by specific systemic questioning and reframing (e.g. Retzer, 2004).

\section{Evidence Base for Family Interventions in General}

We selected three meta-analyses (Claxton, Onwumere, \& Fornells-Ambrojo, 2017; NCCMH, 2014; Pharoah, Mari, Rathbone, \& Wong, 2010) from a pool of four available ones. These did not differentiate between different types of family interventions and thus report omnibus effects, with the bulk of the interventions covered in these analyses being psychoeducational in nature, with or without additional skill training.

As can be seen in Table 1, short-term benefits were mixed, but family interventions demonstrated significant long-term benefits over any control conditions on overall symptoms in any of the three meta-analyses. The effects on positive and negative symptoms were short-term in nature (NCCMH, 2014). For relapse and rehospitalisation the majority of the effects were significant and in the moderate to large range, both at post therapy and at follow-ups, although the long-term effects were non-consistent. Small to moderate effects were also found for short- (Claxton et al., 2017; NCCMH, 2014) and long-term functioning (NCCMH, 2014; Pharoah et al., 2010). 
In order to provide a picture on differential effectiveness, we reviewed three additional meta-analyses each focusing on one of the three specific subtypes, psychoeducative family interventions (Lincoln, Wilhelm, \& Nestoriuc, 2007), comprehensive programs including skilltraining (Pfammatter, Junghan, \& Brenner, 2006) and systemic approaches (Pinquart, Oslejsek, \& Teubert, 2016). Moreover, the NICE meta-analysis (NCCMH, 2014) provided a sub-analysis for psychoeducative interventions that included the family.

As can be seen in Table 1, psychoeducative family interventions demonstrated no significant effect on any of the symptom measures (Lincoln et al., 2007; NCCMH, 2014), but a significant small follow-up effect on relapse and rehospitalisation (combined) in one meta-analysis (ES = 0.48; Lincoln et al., 2007) but not in the other (NCCMH, 2014).

For comprehensive programmes including skill-trainings, one meta-analysis (Pfammatter et al., 2006) demonstrated a small follow-up effect on general psychopathology, relapse and rehospitalisation and a short-term benefit on functioning.

For systemic family approaches there was an overall significant effect on all outcome measures combined, without differentiating between the different outcomes (Pinquart et al., 2016). 


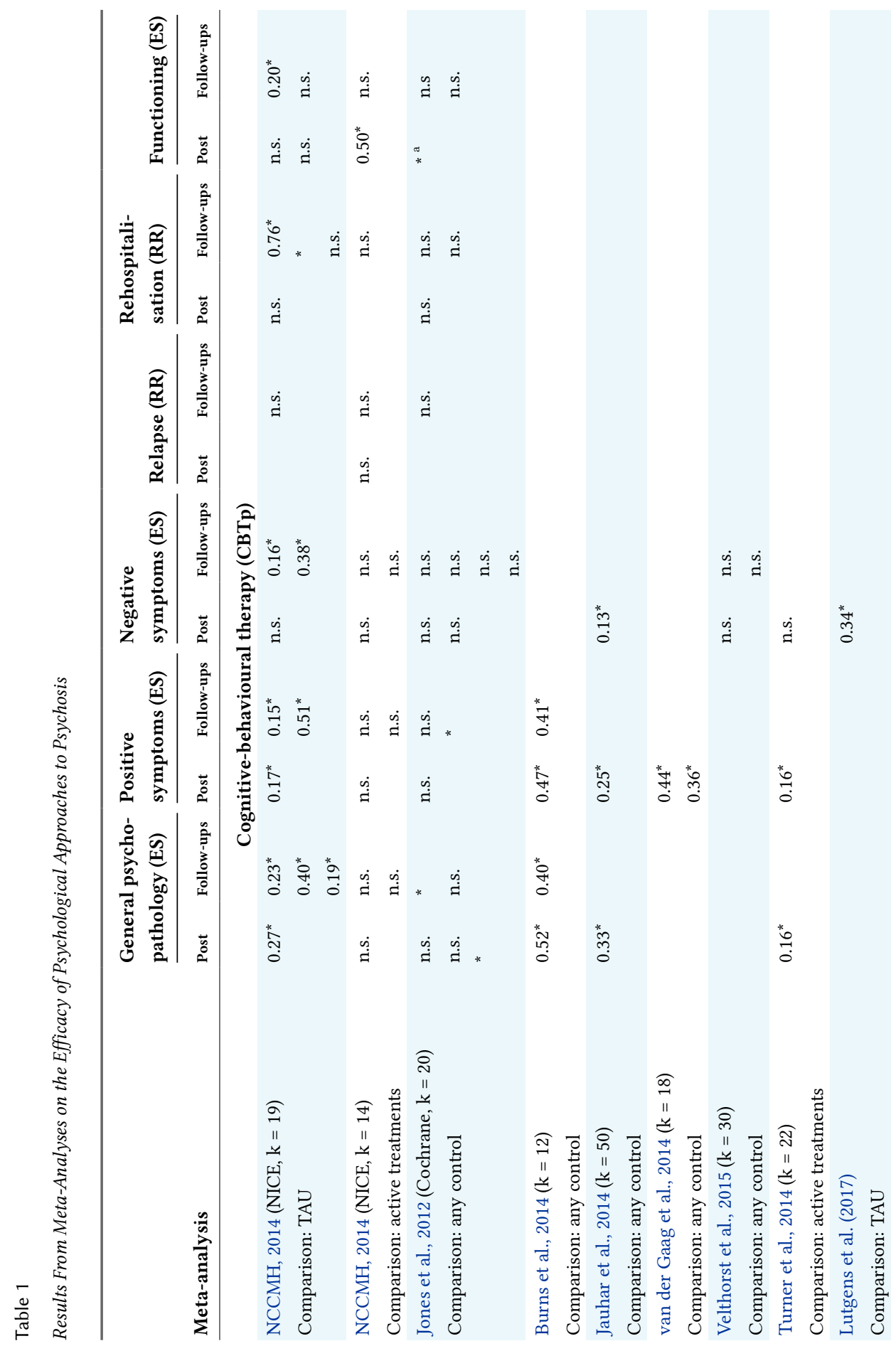




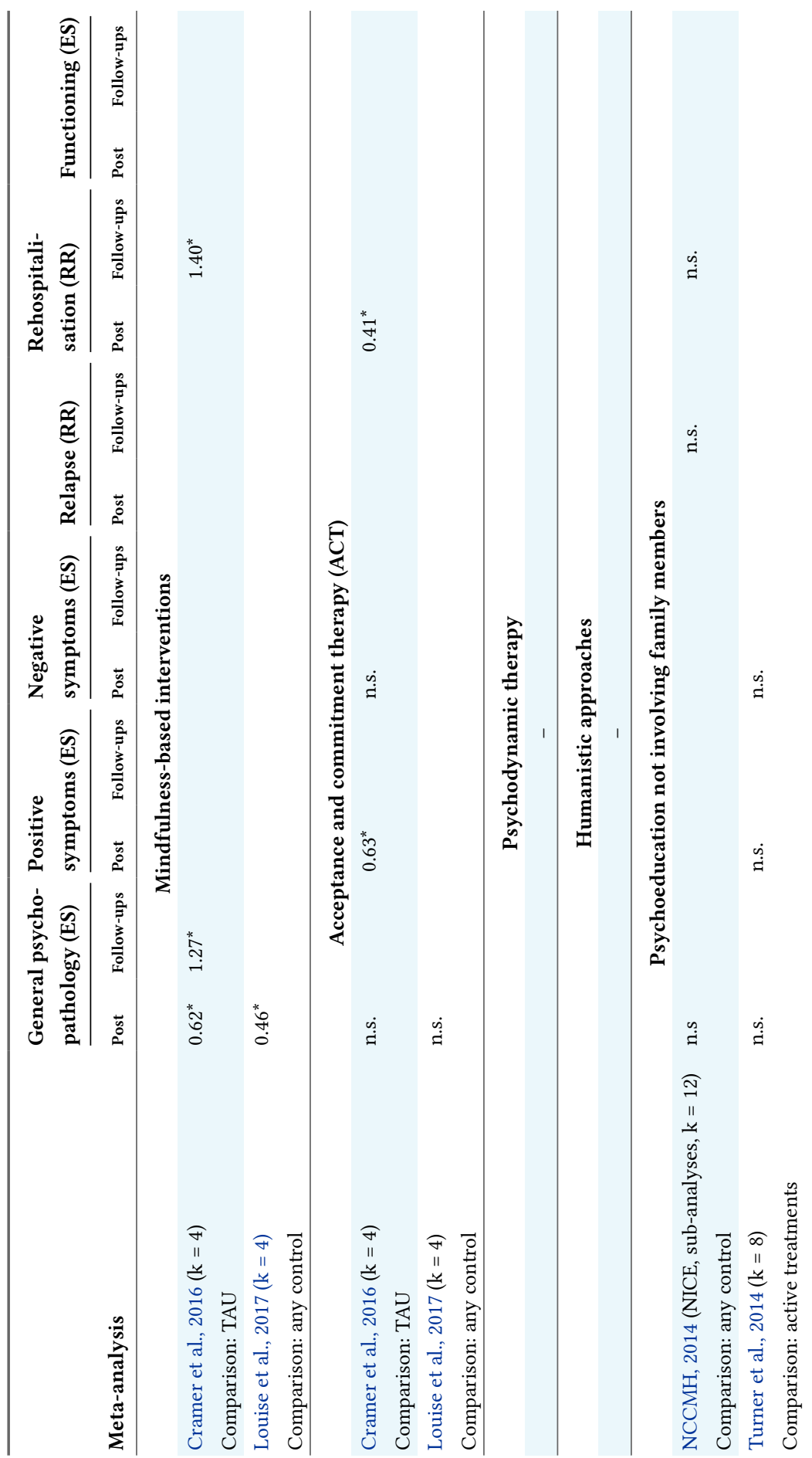




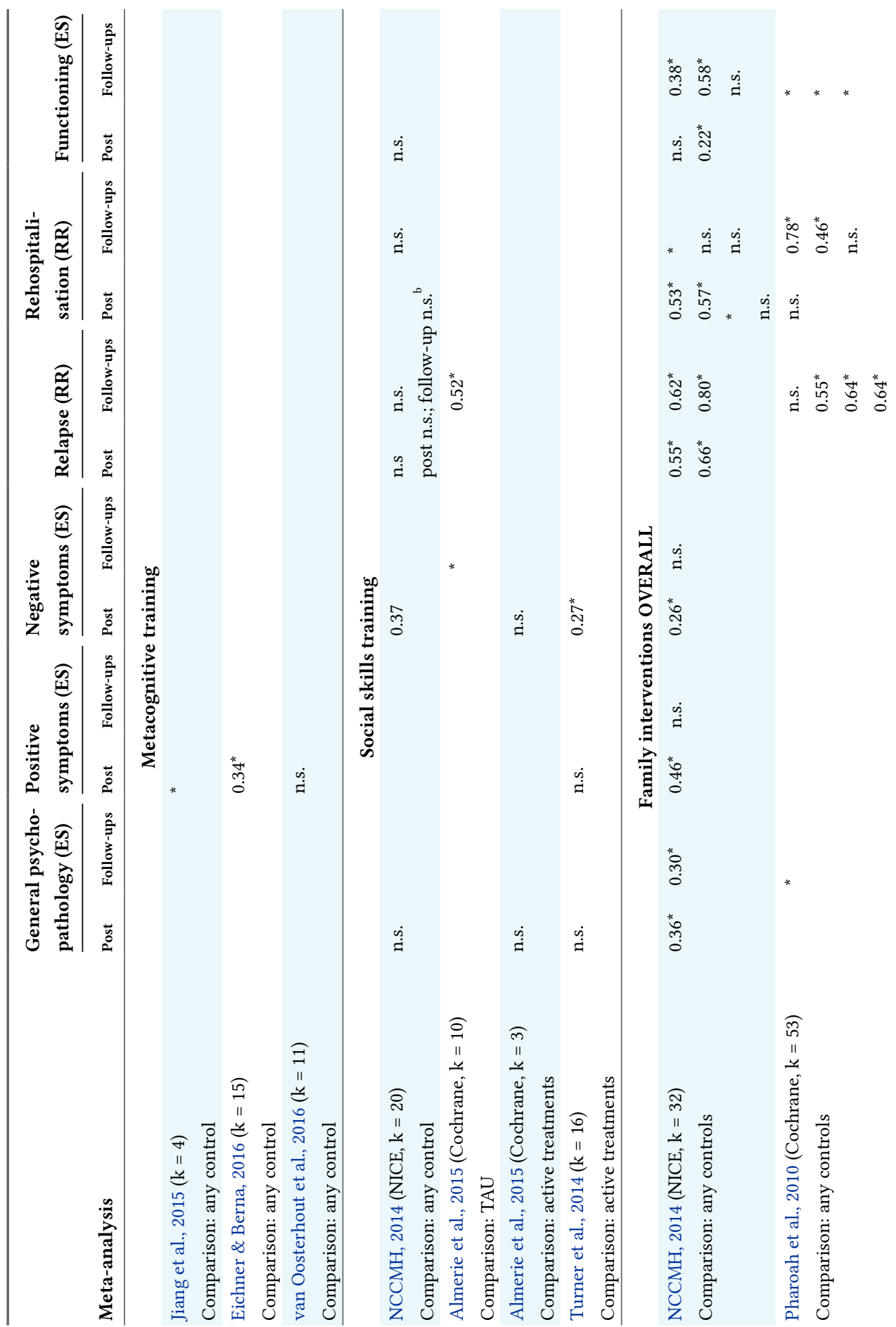




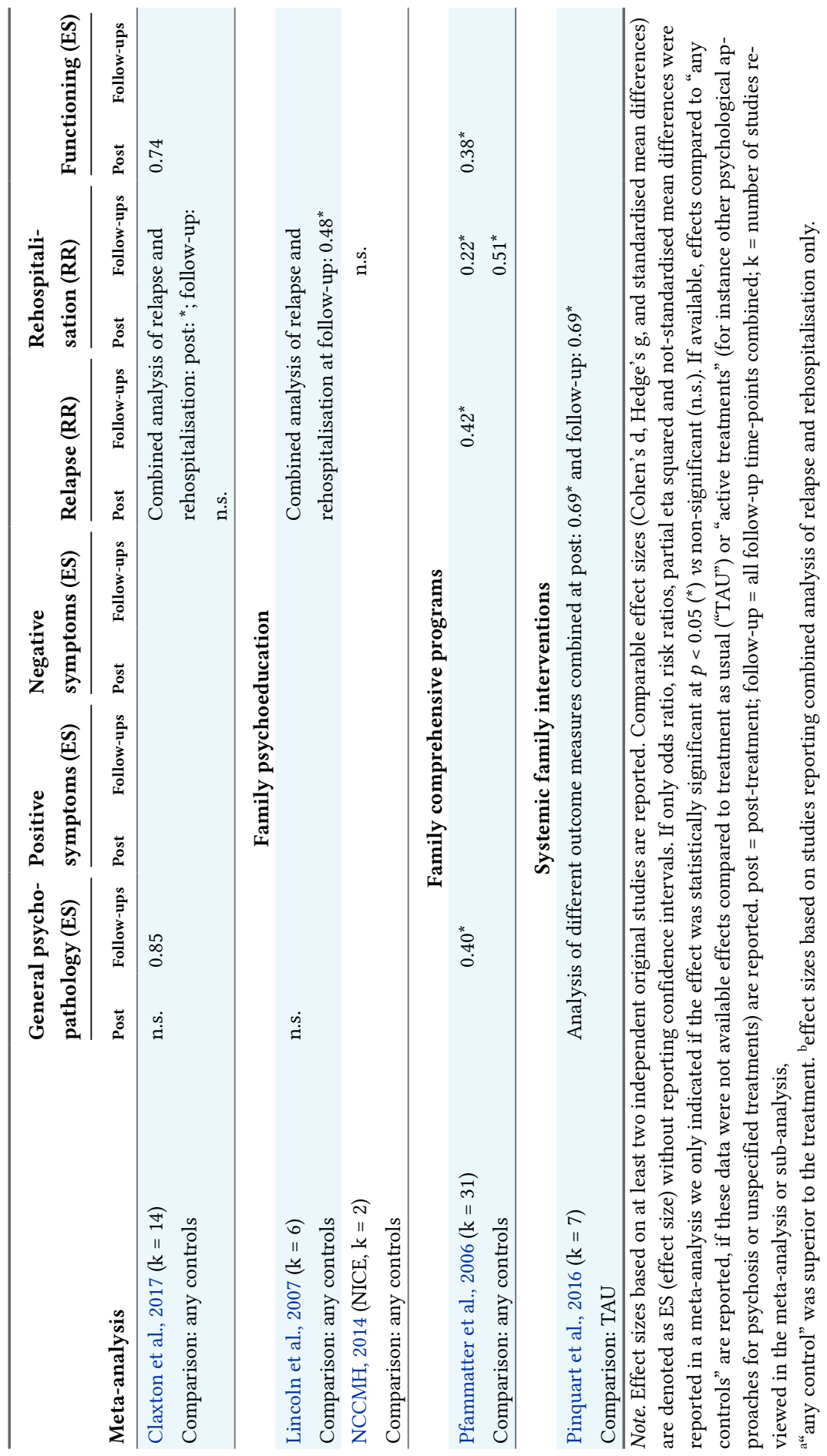




\section{Discussion}

As has become apparent from this review, there are now a variety of different psychological interventions available, of which the majority have a good evidence base for the outcomes that they focus on primarily. If the aim is to reduce general psychopathology or positive symptoms, CBT has the strongest evidence-base both in terms of the number of studies conducted and in regard to the robustness of effects over follow-up periods. Other approaches, such as acceptance and commitment therapy, mindfulness-based approaches, and meta-cognitive training are also promising for these outcomes. Negative symptoms, however, appear to respond better to social skills trainings.

Family interventions are also well-researched and appear to be effective for a broader array of outcomes, including relapse and rehospitalisation as well as functioning. Within family interventions, the strongest effects are found for a combination of psychoeducative and skill-training with families, although it needs noting that this specific combination was only the focus in one meta-analysis. Systemic approaches are also promising, but more high-quality randomised controlled trials are necessary to ascertain their effectiveness for different types of outcomes. There was no convincing evidence for patientdirected psychoeducation (without family involvement) despite the fact that this approach is widespread. However, it may be more difficult to construct a fair evaluation of this approach in RCTs because any control condition is likely to involve psychoeducation to a certain extent. Psychodynamic therapies and humanistic approaches were also not found to be effective, but more RCTs are required in order to draw definite conclusions in this regard.

No approach has a consistently good evidence-base for the entire range of outcomes investigated. This may be partly due to the fact that different types of interventions have focused on different types of outcomes. For example, family interventions have a traditional focus on relapse, whereas CBT focusses on the positive symptoms. Thus, studies investigating these approaches did not consistently include a wider spectrum of outcome measures. More RCTs focusing on the full spectrum of outcome areas are required in order to understand whether different approaches are truly differentially effective. Also, with the exception of a few large effect sizes for family interventions, the effect sizes were largely in the small to marginally moderate range - and thus no higher than those found for pharmacotherapy. However, all original studies in the meta-analyses included here are based on designs that compare psychological interventions combined with medication to medication alone or to medication combined with an additional control condition. Thus, the effects need to be interpreted as "add-on" effects to medication and cannot be directly compared with the effect sizes for medication. So far, it is unclear whether psychological therapy would fare better or worse without the combination with medication as this question has not been investigated. 


\section{Limitations of This Analysis}

The wide scope of interventions reviewed comes at the price of detail. For reasons of space, we did not include the specific search-terms or provide a full account of each of the meta-analyses excluded along with the reasons for in- or exclusion. Also, we did not report the evidence available for questions regarding specific subgroups, formats (e.g. group versus individual, short versus long) or settings (e.g. is family intervention more effective when delivered to individual families versus in groups of families). In Table 1, we focused on the comparison to all control conditions for reasons of brevity and in order to be able to compare different approaches for which such distinctions were not always available. Naturally, differentiating between comparisons to TAU versus active controls is more conclusive and therefore these distinctions were made in the section on CBT for which they are consistently available. Moreover, we abstained from detail in the reporting of effect-sizes (e.g., we did not report standard-deviations, the type of effects, or the number of studies for each comparison). Finally, we disregarded any reported effect-size based on one original study only. Readers seeking more detailed evidence reports are referred to the British or German guidelines (Lincoln et al., 2019; NCCMH, 2014), and to the original meta-analyses cited.

The method as such, a summary of meta-analyses, also has its limitations due to the overlap between meta-analyses. Moreover, the differences in methodological rigour, the inclusion criteria, and the classification of therapy approaches (e.g. inconsistency in what is counted as CBT) result in high levels of heterogeneity in the findings and make it difficult to directly compare different meta-analyses. We attempted to control this bias to a certain extent by disregarding meta-analyses with strong overlap or questionable quality. Another limitation is that the focus on meta-analyses does not provide information on psychological approaches, that are not represented well in the meta-analytic literature. Finally, the continuous accumulation of further evidence renders meta-analyses and reviews outdated at an increasing speed and several new ones have been published since finalizing the selection for this overview.

In this context, it is also worth mentioning a recent meta-analysis that also approached the question of the effectiveness of different psychological approaches to psychosis (Bighelli et al., 2018). This network meta-analysis aggregated data on the level of individual trials on CBT, metacognitive training, mindfulness and acceptance and commitment therapy among other approaches. Similar to our findings, CBT was the most represented among the included treatments and was found to have significant efficacy in comparison with treatment as usual for positive, overall and negative symptoms and functioning. It also showed higher efficacy in comparison with inactive control conditions for positive symptoms whereas there was no convincing proof of efficacy of other treatments. Thus, CBT fared slightly better, even, than in our approach, while third-wave approaches and meta-cognitive therapy were less well supported. Family interventions were not included. 


\section{Final Conclusions}

The variety of efficacious interventions available for psychotic disorders is reassuring. Unfortunately, however, efficacy studies and clinical guidelines alone do not guarantee the implementation of evidence-based interventions, in routine clinical practice (Pilling \& Price, 2006). For example, despite the NICE guideline recommendation to offer CBT to all patients with psychosis, only a minority of eligible patients with psychosis are being offered CBT in the UK (Prytys, Garety, Jolley, Onwumere, \& Craig, 2011). In Germany, studies indicate that only a minority of psychosis patients have access to evidence-based psychotherapy (Schlier \& Lincoln, 2016). To our knowledge, this serious implementation problem of evidence-based interventions is not restricted to Germany and the UK. Thus, although further high quality RCTs focusing on the full spectrum of outcomes are needed, the most relevant challenge to date is that of implementation.

Funding: The authors have no funding to report.

Competing Interests: TL is section editor of Clinical Psychology in Europe but played no editorial role for this particular article.

Acknowledgments: The authors have no support to report.

\section{References}

Almerie, M. Q., Al Marhi, M. O., Jawoosh, M., Alsabbagh, M., Matar, H. E., Maayan, N., \& Bergman, H. (2015). Social skills programmes for schizophrenia. Cochrane Database of Systematic Reviews, 6, Article CD009006. https://doi.org/10.1002/14651858.CD009006.pub2

Bellack, A. S., Mueser, K. T., Gingerich, S., \& Agresta, J. (2013). Social skills training for schizophrenia: A step-by-step guide (2nd ed.). New York, NY, USA: Guilford.

Bighelli, I., Salanti, G., Huhn, M., Schneider-Thoma, J., Krause, M., Reitmeir, C., . . Leucht, S. (2018). Psychological interventions to reduce positive symptoms in schizophrenia: Systematic review and network meta-analysis. World Psychiatry: Official fournal of the World Psychiatric Association (WPA), 17(3), 316-329. https://doi.org/10.1002/wps.20577

Bion, W. R. (1962). The psychoanalytic theory of thinking: II. A theory of thinking. The International Journal of Psycho-Analysis, 43, 306-310.

Brähler, C., Harper, J., \& Gilbert, P. (2013). Compassion focused group therapy for recovery after psychosis. In C. Steel (Ed.), CBT for schizophrenia: Evidence-based interventions and future directions (pp. 236-266). Chichester, United Kingdom: Wiley-Blackwell.

Burns, A. M. N., Erickson, D. H., \& Brenner, C. A. (2014). Cognitive-Behavioral Therapy for medication-resistant psychosis: A meta-analytic review. Psychiatric Services, 65(7), 874-880. https://doi.org/10.1176/appi.ps.201300213 
Butzlaff, R. L., \& Hooley, J. M. (1998). Expressed emotion and psychiatric relapse: A meta-analysis. Archives of General Psychiatry, 55(6), 547-552. https://doi.org/10.1001/archpsyc.55.6.547

Chadwick, P. (2014). Mindfulness for psychosis. The British fournal of Psychiatry, 204(5), 333-334. https://doi.org/10.1192/bjp.bp.113.136044

Claxton, M., Onwumere, J., \& Fornells-Ambrojo, M. (2017). Do family interventions improve outcomes in early psychosis? A systematic review and meta-analysis. Frontiers in Psychology, 8 , Article 371. https://doi.org/10.3389/fpsyg.2017.00371

Cooke, A. (Ed.). (2014). Understanding psychosis and schizophrenia: Why people sometimes hear voices, believe things that others find strange, or appear out of touch with reality, and what can help. Leicester, United Kingdom: British Psychological Society. Retrieved from https://www1.bps.org.uk/networks-and-communities/member-microsite/division-clinicalpsychology/understanding-psychosis-and-schizophrenia

Cramer, H., Lauche, R., Haller, H., Langhorst, J., \& Dobos, G. (2016). Mindfulness- and acceptancebased interventions for psychosis: A systematic review and meta-analysis. Global Advances in Health and Medicine: Improving Healthcare Outcomes Worldwide, 5(1), 30-43. https://doi.org/10.7453/gahmj.2015.083

Depp, C. A., Moore, R. C., Perivoliotis, D., Holden, J. L., Swendsen, J., \& Granholm, E. L. (2016). Social behavior, interaction appraisals, and suicidal ideation in schizophrenia: The dangers of being alone. Schizophrenia Research, 172(1-3), 195-200. https://doi.org/10.1016/j.schres.2016.02.028

Dixon, L., Adams, C., \& Lucksted, A. (2000). Update on family psychoeducation for schizophrenia. Schizophrenia Bulletin, 26(1), 5-20. https://doi.org/10.1093/oxfordjournals.schbul.a033446

Eichner, C., \& Berna, F. (2016). Acceptance and efficacy of Metacognitive Training (MCT) on positive symptoms and delusions in patients with schizophrenia: A meta-analysis taking into account important moderators. Schizophrenia Bulletin, 42(4), 952-962.

https://doi.org/10.1093/schbul/sbv225

Falloon, I. R. H., Boyd, J. L., \& McGill, C. W. (1984). Family care of schizophrenia. New York, NY, USA: Guilford.

Federn, P. (1952). The ego as subject and object in narcissism. In Ego psychology and the psychoses (pp. 283-322). London, United Kingdom: Imago. (Original work published 1928)

Fowler, D., Garety, P., \& Kuipers, E. (1995). Cognitive behaviour therapy for psychosis: Theory and practice. Chichester, United Kingdom: Wiley.

Garety, P. A., \& Freeman, D. (1999). Cognitive approaches to delusions: A critical review of theories and evidence. British fournal of Clinical Psychology, 38(2), 113-154.

https://doi.org/10.1348/014466599162700

Garety, P. A., Kuipers, L., Fowler, D., Freeman, D., \& Bebbington, P. (2001). A cognitive model of the positive symptoms of psychosis. Psychological Medicine, 31(2), 189-195. https://doi.org/10.1017/S0033291701003312

Gendlin, E. T. (1962). Client-centered developments and work with schizophrenics. fournal of Counseling Psychology, 9(3), 205-212. https://doi.org/10.1037/h0047248 
Gilbert, P., \& Procter, S. (2006). Compassionate mind training for people with high shame and selfcriticism: Overview and pilot study of a group therapy approach. Clinical Psychology \& Psychotherapy, 13(6), 353-379. https://doi.org/10.1002/cpp.507

Gumley, A. I., MacBeth, A., Reilly, J. D., O’Grady, M., White, R. G., McLeod, H., . . Power, K. G. (2015). Fear of recurrence: Results of a randomized trial of relapse detection in schizophrenia. British fournal of Clinical Psychology, 54(1), 49-62. https://doi.org/10.1111/bjc.12060

Hayes, S. C., \& Hofmann, S. G. (2017). The third wave of cognitive behavioral therapy and the rise of process-based care. World Psychiatry: Official fournal of the World Psychiatric Association (WPA), 16(3), 245-246. https://doi.org/10.1002/wps.20442

Hayes, S. C., Strosahl, K. D., \& Wilson, K. G. (1999). Acceptance and commitment therapy: An experiential approach to behavior change. New York, NY, USA: Guilford Press.

Jauhar, S., McKenna, P. J., Radua, J., Fung, E., Salvador, R., \& Laws, K. R. (2014). Cognitivebehavioural therapy for the symptoms of schizophrenia: Systematic review and meta-analysis with examination of potential bias. The British fournal of Psychiatry, 204(1), 20-29. https://doi.org/10.1192/bjp.bp.112.116285

Jiang, J., Zhang, L., Zhu, Z., Li, W., \& Li, C. (2015). Metacognitive training for schizophrenia: A systematic review. Shanghai Archives of Psychiatry, 27(3), 149-157.

https://doi.org/10.11919/j.issn.1002-0829.215065

Jones, C., Hacker, D., Cormac, I., Meaden, A., \& Irving, C. B. (2012). Cognitive behavioural therapy versus other psychosocial treatments for schizophrenia. Cochrane Database of Systematic Reviews, 4. https://doi.org/10.1002/14651858.CD008712.pub2

Lal, S., Malla, A., Marandola, G., Thériault, J., Tibbo, P., Manchanda, R., .. Banks, N. (2019). "Worried about relapse": Family members' experiences and perspectives of relapse in firstepisode psychosis. Early Intervention in Psychiatry, 13(1), 24-29. https://doi.org/10.1111/eip.12440

Lempa, G., Montag, C., \& von Haebler, D. (2013). Auf dem Weg zu einem Manual der psychodynamischen Psychosentherapie [On the way towards a manual for psychodynamic therapy of psychoses]. Psychotherapeut, 58(4), 327-338.

https://doi.org/10.1007/s00278-013-0998-0

Leucht, S., Tardy, M., Komossa, K., Heres, S., Kissling, W., Salanti, G., \& Davis, J. M. (2012). Antipsychotic drugs versus placebo for relapse prevention in schizophrenia: A systematic review and meta-analysis. Lancet, 379(9831), 2063-2071. https://doi.org/10.1016/S0140-6736(12)60239-6

Lincoln, T. M. (2007). Relevant dimensions of delusions: Continuing the continuum versus category debate. Schizophrenia Research, 93(1-3), 211-220. https://doi.org/10.1016/j.schres.2007.02.013

Lincoln, T. M., Pedersen, A., Hahlweg, K., Wiedl, K.-H., \& Frantz, I. (2019). Evidenzbasierte Leitlinie zur Psychotherapie von Schizophrenie und anderen psychotischen Störungen. Göttingen, Germany: Hogrefe. 
Lincoln, T. M., Wilhelm, K., \& Nestoriuc, Y. (2007). Effectiveness of psychoeducation for relapse, symptoms, knowledge, adherence and functioning in psychotic disorders: A meta-analysis. Schizophrenia Research, 96(1-3), 232-245. https://doi.org/10.1016/j.schres.2007.07.022

Louise, S., Fitzpatrick, M., Strauss, C., Rossell, S. L., \& Thomas, N. (2018). Mindfulness- and acceptance-based interventions for psychosis: Our current understanding and a meta-analysis. Schizophrenia Research, 192, 57-63. https://doi.org/10.1016/j.schres.2017.05.023

Lucksted, A., McFarlane, W. R., Downing, D., \& Dixon, L. (2012). Recent developments in family psychoeducation as an evidence-based practice. Fournal of Marital and Family Therapy, 38(1), 101-121. https://doi.org/10.1111/j.1752-0606.2011.00256.x

Lutgens, D., Gariepy, G., \& Malla, A. (2017). Psychological and psychosocial interventions for negative symptoms in psychosis: Systematic review and meta-analysis. The British fournal of Psychiatry, 210(5), 324-332. https://doi.org/10.1192/bjp.bp.116.197103

Malmberg, L., Fenton, M., \& Rathbone, J. (2001). Individual psychodynamic psychotherapy and psychoanalysis for schizophrenia and severe mental illness. Cochrane Database of Systematic Reviews, 3. https://doi.org/10.1002/14651858.CD001360

Mondrup, L., \& Rosenbaum, B. (2009). Interpersonal problems in the prodromal state of schizophrenia: An exploratory study. Psychosis, 2(3), 238-247. https://doi.org/10.1080/17522430903288340

Moritz, S., \& Woodward, T. S. (2007). Metacognitive training for patients with schizophrenia (MCT): Manual. Hamburg, Germany: VanHam Campus.

Morrison, A. P., Hutton, P., Shiers, D., \& Turkington, D. (2012). Antipsychotics: Is it time to introduce patient choice? The British fournal of Psychiatry, 201(2), 83-84. https://doi.org/10.1192/bjp.bp.112.112110

Morrison, A. P., Renton, J. C., Dunn, H., Williams, S., \& Bentall, R. P. (2004). Cognitive therapy for psychosis: A formulation-based approach. New York, NY, USA: Brunner-Routledge.

Murray, R. M., Quattrone, D., Natesan, S., van Os, J., Nordentoft, M., Howes, O., . . Taylor, D. (2016). Should psychiatrists be more cautious about the long-term prophylactic use of antipsychotics? The British fournal of Psychiatry, 209(5), 361-365.

https://doi.org/10.1192/bjp.bp.116.182683

${ }^{*} \mathrm{NCCMH}$. (2014). Psychosis and schizophrenia in adults: The NICE guideline on treatment and management (NICE Clinical Guideline 178). London, United Kingdom: NICE.

O’Donoghue, E. K., Morris, E. M. J., Oliver, J. E., Johns, L. C., \& Hayes, S. C. (2018). ACT for psychosis recovery: A practical manual for group-based interventions using acceptance and commitment therapy. Oakland, CA, USA: New Harbinger.

Paksarian, D., Mojtabai, R., Kotov, R., Cullen, B., Nugent, K. L., \& Bromet, E. J. (2014). Perceived trauma during hospitalization and treatment participation among individuals with psychotic disorders. Psychiatric Services, 65(2), 266-269. https://doi.org/10.1176/appi.ps.201200556

Pfammatter, M., Junghan, U. M., \& Brenner, H. D. (2006). Efficacy of psychological therapy in schizophrenia: Conclusions from meta-analyses. Schizophrenia Bulletin, 32(Suppl 1), S64-S80. https://doi.org/10.1093/schbul/sbl030 
Pharoah, F., Mari, J., Rathbone, J., \& Wong, W. (2010). Family intervention for schizophrenia. Cochrane Database of Systematic Reviews, 12. https://doi.org/10.1002/14651858.CD000088.pub2

Pilling, S., \& Price, K. (2006). Developing and implementing clinical guidelines: Lessons from the NICE Schizophrenia Guideline. Epidemiology and Psychiatric Sciences, 15(2), 109-116. https://doi.org/10.1017/S1121189X00004309

Pinquart, M., Oslejsek, B., \& Teubert, D. (2016). Efficacy of systemic therapy on adults with mental disorders: A meta-analysis. Psychotherapy Research, 26(2), 241-257. https://doi.org/10.1080/10503307.2014.935830

Prytys, M., Garety, P. A., Jolley, S., Onwumere, J., \& Craig, T. (2011). Implementing the nice guideline for schizophrenia recommendations for psychological therapies: A qualitative analysis of the attitudes of CMHT staff. Clinical Psychology \& Psychotherapy, 18(1), 48-59. https://doi.org/10.1002/cpp.691

Retzer, A. (2004). Systemische Familientherapie der Psychosen. Göttingen, Germany: Hogrefe.

Rogers, C. R., Gendlin, E. T., Kiesler, D. J., \& Truax, C. (1967). The therapeutic relationship and its impact: A study of psychotherapy with schizophrenics. Madison, WI, USA: University of Wisconsin Press.

Schlier, B., \& Lincoln, T. M. (2016). Blinde Flecken? Der Einfluss von Stigma auf die psychotherapeutische Versorgung von Menschen mit Schizophrenie. Verhaltenstherapie, 26(4), 279-290. https://doi.org/10.1159/000450694

Treanor, L., Lobban, F., \& Barrowclough, C. (2013). Relatives' responses to psychosis: An exploratory investigation of low expressed emotion relatives. Psychology and Psychotherapy: Theory, Research and Practice, 86(2), 197-211. https://doi.org/10.1111/j.2044-8341.2011.02055.x

Turner, D. T., van der Gaag, M., Karyotaki, E., \& Cuijpers, P. (2014). Psychological interventions for psychosis: A meta-analysis of comparative outcome studies. The American fournal of Psychiatry, 171(5), 523-538. https://doi.org/10.1176/appi.ajp.2013.13081159

van der Gaag, M., Valmaggia, L. R., \& Smit, F. (2014). The effects of individually tailored formulation-based cognitive behavioural therapy in auditory hallucinations and delusions: A meta-analysis. Schizophrenia Research, 156(1), 30-37. https://doi.org/10.1016/j.schres.2014.03.016

van Oosterhout, B., Smit, F., Krabbendam, L., Castelein, S., Staring, A. B. P., \& van der Gaag, M. (2016). Metacognitive training for schizophrenia spectrum patients: A meta-analysis on outcome studies. Psychological Medicine, 46(1), 47-57.

https://doi.org/10.1017/S0033291715001105

Velthorst, E., Koeter, M., van der Gaag, M., Nieman, D. H., Fett, A. K. J., Smit, F., . . de Haan, L. (2015). Adapted cognitive-behavioural therapy required for targeting negative symptoms in schizophrenia: Meta-analysis and meta-regression. Psychological Medicine, 45(3), 453-465. https://doi.org/10.1017/S0033291714001147

von Haebler, D., \& Freyberger, H. (2013). Psychotherapie für Menschen mit Psychosen ist möglich [Psychotherapy for people with psychoses is possible]. Psychotherapeut, 58(4), 325-326. https://doi.org/10.1007/s00278-013-0994-4 
Wade, M., Tai, S., Awenat, Y., \& Haddock, G. (2017). A systematic review of service-user reasons for adherence and nonadherence to neuroleptic medication in psychosis. Clinical Psychology Review, 51, 75-95. https://doi.org/10.1016/j.cpr.2016.10.009

Winnicott, D. W. (1991). Die Angst vor dem Zusammenbruch. Psyche, 45(12), 1116-1126.

Woodward, T. S., Jung, K., Hwang, H., Yin, J., Taylor, L., Menon, M., . . Erickson, D. (2014). Symptom dimensions of the psychotic symptom rating scales in psychosis: A multisite study. Schizophrenia Bulletin, 40(Suppl 4), S265-S274. https://doi.org/10.1093/schbul/sbu014

Wright, N. P., Turkington, D., Kelly, O. P., Davies, D., Jacobs, A. M., \& Hopton, J. (2014). Treating psychosis: A clinician's guide to integrating acceptance and commitment therapy, compassionfocused therapy, and mindfulness approaches within the cognitive behavioral therapy tradition. Oakland, CA, USA: New Harbinger Publications.

\section{Appendix: Not Included Meta-Analyses}

\section{Cognitive-Behavioral Therapy (CBTp)}

Bird, V., Premkumar, P., Kendall, T., Whittington, C., Mitchell, J., \& Kuipers, E. (2010). Early intervention services, cognitive-behavioural therapy and family intervention in early psychosis: Systematic review. The British fournal of Psychiatry, 197(5), 350-356.

https://doi.org/10.1192/bjp.bp.109.074526

Lynch, D., Laws, K. R., \& McKenna, P. J. (2010). Cognitive behavioural therapy for major psychiatric disorder: Does it really work? A meta-analytical review of well-controlled trials. Psychological Medicine, 40(1), 9-24. https://doi.org/10.1017/S003329170900590X

Mehl, S., Werner, D., \& Lincoln, T. M. (2015). Does cognitive behaviour therapy for psychosis (CBTP) show a sustainable effect on delusions? A meta-analysis. Frontiers in Psychology, 6, Article 1450. https://doi.org/10.3389/fpsyg.2015.01450

Naeem, F., Khoury, B., Munshi, T., Ayub, M., Lecomte, T., Kingdon, D., \& Farooq, S. (2016). Brief cognitive behavioral therapy for psychosis (CBTP) for schizophrenia: Literature review and meta-analysis. International fournal of Cognitive Therapy, 9(1), 73-86.

https://doi.org/doi.org/10.1521/ijct_2016_09_04

Newton-Howes, G., \& Wood, R. (2013). Cognitive behavioural therapy and the psychopathology of schizophrenia: Systematic review and meta-analysis. Psychology and Psychotherapy: Theory, Research and Practice, 86(2), 127-138. https://doi.org/10.1111/j.2044-8341.2011.02048.x

Sarin, F., Wallin, L., \& Widerlöv, B. (2011). Cognitive behavior therapy for schizophrenia: A metaanalytical review of randomized controlled trials. Nordic fournal of Psychiatry, 65(3), 162-174. https://doi.org/10.3109/08039488.2011.577188 


\section{Mindfulness-Based Interventions}

Khoury, B., Lecomte, T., Gaudiano, B. A., \& Paquin, K. (2013). Mindfulness interventions for psychosis: A meta-analysis. Schizophrenia Research, 150(1), 176-184. https://doi.org/10.1016/j.schres.2013.07.055

Tonarelli, S. B., Pasillas, R., Alvarado, L., Dwivedi, A., \& Cancellare, A. (2016). Acceptance and commitment therapy compared to treatment as usual in psychosis: A systematic review and meta-analysis. Journal of Psychiatry, 19(3), Article 1000366.

https://doi.org/10.4172/2378-5756.1000366

\section{Psychodynamic Therapy}

Malmberg, L., Fenton, M., \& Rathbone, J. (2001). Individual psychodynamic psychotherapy and psychoanalysis for schizophrenia and severe mental illness. Cochrane Database of Systematic Reviews, 3. https://doi.org/10.1002/14651858.CD001360

NCCMH. (2014). Psychosis and schizophrenia in adults: The NICE guideline on treatment and management (NICE Clinical Guideline 178). London, United Kingdom: NICE.

\section{Psychoeducation Without Family}

Xia, J., Merinder, L. B., \& Belgamwar, M. R. (2011). Psychoeducation for schizophrenia. Cochrane Database of Systematic Reviews, 6. https://doi.org/10.1002/14651858.CD002831.pub2

Zou, H., Li, Z., Nolan, M. T., Arthur, D., Wang, H., \& Hu, L. (2013). Self-management education interventions for persons with schizophrenia: A meta-analysis. International fournal of Mental Health Nursing, 22(3), 256-271. https://doi.org/10.1111/j.1447-0349.2012.00863.x

\section{Family Interventions OVERALL}

Bird, V., Premkumar, P., Kendall, T., Whittington, C., Mitchell, J., \& Kuipers, E. (2010). Early intervention services, cognitive-behavioural therapy and family intervention in early psychosis: Systematic review. The British fournal of Psychiatry, 197(5), 350-356. https://doi.org/10.1192/bjp.bp.109.074526

Okpokoro, U., Adams, C. E., \& Sampson, S. (2014). Family intervention (brief) for schizophrenia. Cochrane Database of Systematic Reviews, 3. https://doi.org/10.1002/14651858.CD009802.pub2 